\title{
Formação de agentes de saúde como instituinte de novos modos de cuidado nos sistemas de saúde e proteção social na Europa: entrevista com Xavier Baylace Fantroa Hastaran
}

Health workers education as institutive of new modes of care in health systems and social protection in Europe: interview with Xavier Baylac and Fantxoa Hastaran

Formación de los trabajadores de salud como instituyendo nuevas modalidades de atención en los sistemas de salud y protección social en Europa: entrevista con Xavier Baylac y Fantxoa Hastaran
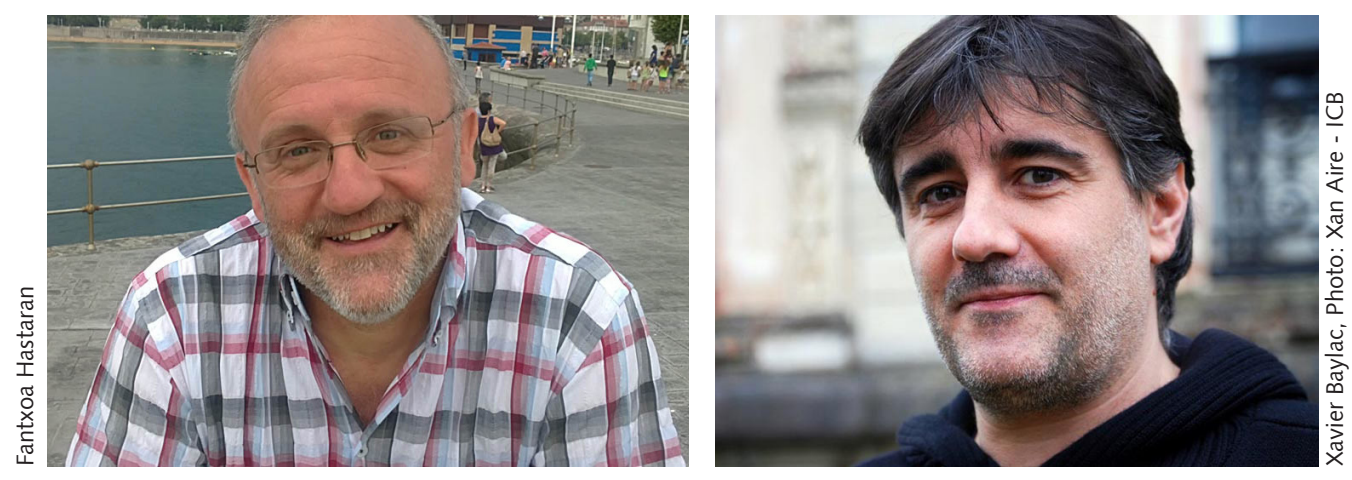

Há uma novidade no cenário europeu no que se refere à formação para trabalhadores dos sistemas social e de saúde. Esta novidade se chama KILT, sigla para o Projeto "Knowledge Identity Language Tools", cujo objetivo é criar ferramentas de apropriação linguística e cultural que servirá para facilitar a relação com a pessoa que está sendo acompanhada por um profissional do serviço de assistência social ou da saúde.

O Projeto KILT é apoiado pela Comunidade Europeia por meio da Diretoria Geral de Educação/Programa para Educação e Formação ao Longo da Vida. Nesta diretoria o "Programa Leonardo da Vinci - transferência de inovação" tem o objetivo de apoiar projetos de formação, procurando dar um impulso aos sistemas de educação e ensino profissional na Europa. Em janeiro de 2013 o grupo que se organizou em torno do projeto KILT se candidata aos recursos deste Programa e é contemplado no apoio ao mesmo. 
Pela sua história e experiência o KILT denuncia o paradoxo de uma formação essencialmente instrumental e a necessidade de educar profissionais que no seu trabalho tenham alta performance nas tecnologias relacionais e sócio-afetivas, como é o caso de cuidados a idosos com Alzheimer no país Basco, França; imigrantes em Emilia-Romagna, Itália; populações rom na Eslováquia, por exemplo. É intervindo neste campo paradoxal que o projeto KILT sugere inovar em ferramentas que possam ser disponibilizadas, mediante projetos formativos, para o trabalho com essas populações, reconhecendo sua diferença, respeitando as singularidades e inserindo-as na paisagem europeia sem violar a sua humanidade.

Partindo de um trabalho singular no País Basco, França, este grupo se articula em uma rede envolvendo grupos de cinco países europeus, que têm em comum o fato de trabalharem com populações em situação de extrema fragilidade, vulneradas e com dificuldades de integração na sociedade europeia. A partir daqui é história.

Esta história e seu desenvolvimento foi contada à Interface, em entrevista concedida a Túlio Franco, no seminário do projeto ocorrido em Edimburgo, Escócia, em julho de 2014, pelo coordenador do projeto KILT, Xavier BAYLAC, do País Basco, França, diretor geral da Association Pour la Formation en Milieu Rural Etcharry Formation Developpement, organismo de formação e de educação de adultos (EDUadlt); e Fantxoa HASTARAN, também do país Basco, França, responsável por projetos na Etcharry Formation Développement.

O Projeto tem a participação das seguintes entidades : I'AFMR Etcharry Formation Développement (coordenador), ator francês de formação e trabalho social. O projeto KILT agrupa atores de natureza diferente e complementares, que são : Institut Culturel Basque - Euskal Kultur Erakundea, ayant

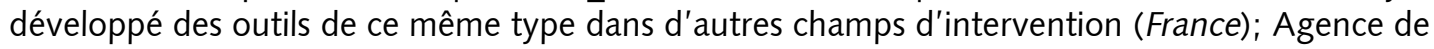
Santé Régionale de la région Emilie-Romagne (Italie) ; CEFAL, organisme de formation en travail social et d'accompagnement socioprofessionnel de Bologne (Italie) ; SPARK, structure de formation en travail social de Kosice (Slovaquie) ; ECKVRNM, organisme à caractère social travaillant auprès des populations rom à Kosice (Slovaquie); NHS LOTHIAN, Hôpital public d'Edimbourg travaillant en grande partie au contact des populations immigrées (Ecosse - Royaume Uni); VHIR - Vall d'Hebron Research Institute, fondation associée à I'hôpital de Barcelone, qui développe déjà des outils de formation de ce type au bénéfice des « agents sociaux » catalans (Catalogne - Espagne).

\section{Interface - Como vocês podem resumir a história do projeto KILT, porque este projeto foi pensado, como vocês fazem para viabilizá-lo na França e na Comunidade Europeia?}

Xavier Baylac - O início da construção do projeto se deu no País Basco, na França, em diversas áreas de atividade de assistentes sociais, nas quais estamos engajados, visando especialmente à área de ajuda à pessoa, uma vez que isto pode se expressar pela atuação dos assistentes sociais que vão ajudar as crianças deficientes, as pessoas autistas e que vão atuar igualmente junto às populações idosas locais, especialmente do País Basco, as quais são cada vez mais atingidas por doenças como o alzheimer, por exemplo e em virtude desta doença nos demos conta de que essas pessoas tinham perdido referências do momento presente, porém mantinham, de uma maneira muito ativa, as referências passadas, entre as quais, em um nível que lhes era muito próprio, se situava a língua. Por outro lado, os profissionais que trabalhavam junto a essas pessoas não eram originários do País Basco e por vezes, nos estabelecimentos, diziam: "este senhor idoso não fala mais, não podemos mais nos comunicar com ele".

Por vezes, alguns utilizavam palavras bascas e então se davam conta de que o idoso, quando a ele se dirigia em basco, recuperava sua capacidade de se comunicar, o que revela, portanto, vide numerosíssimos exemplos, como de fato havia, um distanciamento entre os assistentes sociais e os trabalhadores da saúde que atuavam junto a esse público dependente. Havia um distanciamento de cultura, de língua, um distanciamento na maneira de se estabelecer uma conexão com o outro, pois todas as formações, tanto no campo da saúde como no campo social, dentro do sistema francês, não integram este parâmetro, uma vez que lidamos com corpus de informação que são teóricos e sobretudo técnicos, mesmo que as pessoas passem pelo modelo de formação francês, no campo social e no 
campo da saúde, o que constitui o que chamamos de "alternância integrativa", isto é, reagrupamentos no centro de informação, por exemplo, teórico, nos estabelecimentos e institutos, uma atividade ininterrupta de ida e volta entre os centros de informação e os espaços profissionais.

Em outras palavras, ainda que esta dimensão profissional exista, a formação em si permanece muito técnica, ou seja, de repente podemos dizer que o outro, o objeto de nosso trabalho, está diante de nós, nós devemos nos organizar para ele, o que não impede que, mesmo que a solução que trazemos seja técnica, não tenhamos espaço para também trabalhar com ele a sua história, identidade ou problemática.

Consideremos pois, que a ideia do projeto, no início, partia da seguinte indagação: será que não poderíamos cogitar de trazer uma outra maneira de formar o profissional, sem colocar em questão o modelo, pois este funciona, e tratar de enriquecer o modelo de formação com uma questão que corresponda a utilizar a identidade do outro, ou seja, do beneficiário, do idoso, do paciente, utilizando isto como uma nova maneira de abordá-lo e de inseri-lo no sistema?

Foi então a partir desta ideia, juntamente com Fantxoa, uma vez que já era nosso costume ter parceiros europeus, que lançamos uma espécie de SOS na Europa dizendo: será que existem outras pessoas que vivenciam este mesmo estado de reflexão? E foi assim que os trabalhadores da saúde, os corsos, os da Catalunha disseram, bem, nós também passamos por este problema, não com o mesmo público, porque o público deles é mais frequentemente o pessoal da mineração, vindo de países estrangeiros, por vezes de países europeus.

Começamos a enxergar parceiros cujo público não era o mesmo que o nosso, mas que lidavam com beneficiários semelhantes, uma vez que havia o mesmo questionamento sobre todas aquelas pessoas, junto às quais trabalhavam, em termos de acompanhamento, para chegar, por um lado, a lhes permitir de permanecerem autônomas, por outro, a lhes permitir de ingressarem em um processo de integração ou de inserção. Todas aquelas pessoas, como hoje em dia nos movemos em planetas diferentes, apesar de estarmos aparentemente no mesmo lugar, estavam em situação de acompanhamento, mas com variantes culturais, e de repente nos tocamos que nossa questão, a questão principal, se aproximava, ou seja, nos fazia chegar um pouco à problemática da língua, já que o outro, na verdade, não nos bloqueia, o que nos bloqueia é a língua, o que nos leva rapidamente a concluir que é inimaginável que assistentes sociais conheçam 196 línguas estrangeiras.

Portanto, já existia uma espécie de barreira lógica, por assim dizer, e ela não estava lá por conta das línguas e quanto mais se elaborava esta questão, a língua, em si, se constituía como parceira para a construção de nosso projeto, uma vez que era certamente um vetor da relação e, num nível mais profundo, o que era necessário dar aos assistentes sociais e aos trabalhadores da saúde era a capacidade de poder assumir, em termos de escuta e igualmente em termos de expressão, diferentes identidades. Foi tudo isto que gerou o projeto.

\footnotetext{
(b) CEFAL (Consorzio Europeo per la Formazione e l'Agggiornamento dei Lavoratori) é uma entidade de formação profissional, com sede em Bolonha, acreditado pela Região Emilia Romagna, Itália.
}

\section{Interface - Como se deu a constituição de uma rede de entidades na Europa, com a qual vocês desenvolvem o projeto KILT?}

Fantxoa - cada um de nós aprendeu a procurar forçosamente outros operadores, outros atores, que parecessem pertinentes em relação ao projeto que estávamos propondo. Foi a CEFAL (b), organismo de formação no trabalho social e de acompanhamento socioprofissional de Bolonha (Italie), que entrou em contato 
com a Agência Sanitária e Social da Região de Emilia Romagna na Itália, e foi esta agência que fez uma ligação com o Hospital de Barcelona e o Hospital de Hamburgo, operando numa relação de parceirorede, que fez com que esta faceta se construísse dessa maneira. E nós tivemos contato com dois outros parceiros, o primeiro foi o Instituto Cultural Basco, dentro de nossa lógica própria em nível dos PaísesBascos e é essencial que um ator cultural questione este enfoque da sensibilidade cultural e um pouco, também antropológica, dos assistentes sociais. Nós também já tínhamos contatos com um parceiro eslovaco e por isto, quando eles nos contataram, nós confirmamos com este parceiro, sabendo que trabalhavam com populações rom.

E foi assim que, entre CEFAL e nós, se construiu uma parceria, hoje com oito membros, de fato, oito parceiros originários de cinco países, a saber Escócia, Eslováquia, Itália, Catalunha-Espanha e nós, na França.

\section{Interface - Voltando à questão pedagógica, Xavier faz uma crítica ao sistema educacional francês, o qual considera muito técnico, com pouca ênfase no desenvolvimento humanitário. Acredito que é um fenômeno generalizado e o projeto que você descreve aqui fala de um processo de mudança da pessoa por meio da educação. Você pode falar um pouco sobre o projeto pedagógico do KILT, o objetivo deste trabalho, e suas referências?}

Xavier Baylac - Efetivamente, sobre a questão da formação dos profissionais por meio das abordagens que realizamos entre os parceiros, guardamos esperanças pedagógicas que já tínhamos, porém mais adiante nos demos conta de que o objetivo era na verdade chegar a formar pessoas com ferramentas que capacitassem para o encontro com o outro. Por isso mesmo podíamos informá-los sobre a formação clássica no tocante às chaves da compreensão antropológica, etnológica, sociológica, podíamos ministrar-lhes cursos de comunicação, isto é, introduzi-los a todos os elementos de comunicação verbal, não verbal, à postura que permitisse, efetivamente, descriptografar os caminhos, as passagens overloques, porém nos demos conta, refletindo sobre isso, que estávamos às voltas com profissionais em exercício, já formados e podíamos ministrar-lhes cursos suplementares, efetivamente, mas não seria útil o risco de lhes dar ferramentas para que eles as utilizassem uma vez mais como ferramentas aleatórias, uma vez que o fundo do problema é a capacidade de fazer evoluir a própria postura, ou seja, de estar ciente de que: Hoje eu tenho uma missão profissional para a qual eu sinto que ela perde em eficiência, minha intervenção profissional não é mais tão eficaz, não é mais tão eficiente como era há dez, 15 ou vinte anos, porque as populações junto às quais eu trabalho estão em realidades cada vez mais mescladas, as problemáticas de saúde se entrecruzam com as problemáticas sociais, com as questões econômicas, com as questões ambientais, a pessoa que eu devo ajudar, hoje, tem um universo de complexidade, por vezes um universo de estranheza, para mim, alguma coisa que me é desconhecida e que neste ponto específico eu tenho que aceitar e descobrir.

Ora, não existe uma outra possibilidade de descobrir alguém, se nós mesmos não aceitarmos de nos colocarmos, não em causa, mas em questão, ou seja, partirmos da indagação de quem eu sou, qual é minha trajetória, de onde venho, e... então qual é meu sistema de valores, de representação, se sou capaz de me questionar, capaz de me alimentar, então eu estou em melhores condições de poder propor esta abertura ao outro e acompanhar o outro em sua abertura, isto é, naquilo que se cruza normalmente, quase diria, na vida, todos os dias, ou seja, o próprio princípio do intercambio.

Uma vez que nos colocamos esses elementos em termos de valor, em relação ao que colocávamos em termos de cultura, digamos que, subitamente, nossa formação parte, ou melhor, ela devia ser inicialmente um processo de evolução das pessoas que íamos formar, se torna mais do que simplesmente utilizá-las em outros parâmetros técnicos, pois era preciso inicialmente que nós as levássemos a se questionar e então ganhar uma espécie de capacidade securizada a fim de aceitar sem parar a curiosidade e o questionamento. 
Para si próprios e porque são capazes de fazê-lo para si próprios, eles também são capazes de gerá-los e de apoiá-lo no outro, no paciente e nos trabalhadores da saúde. O que eles querem daí, o processo pedagógico, foi determinado um pouco como uma trajetória da mudança.

Em função dos países falamos de trajetória, de caminhada, de caminho, mas foi mais exatamente como uma espécie de busca que vai se processar mediante diferentes etapas, as quais vão fazer com que eu me requestione, de repente, eu sou capaz, talvez, de ficar de uma maneira diferente na escuta, de identificar as coisas em mim, no outro, do ponto de vista de minha profissão. Talvez eu queira me reposicionar diferentemente, me adaptar, mas sobretudo eu quero compreender que eu mesmo, enquanto pessoa, sou singular e aquele que eu sou hoje, não era o mesmo há seis meses, dois anos e não será o mesmo personagem dentro de dois ou três anos. Isto quer dizer que, efetivamente, sem parar, meu processo de evolução, eu mesmo não sou senão uma trajetória de minha evolução, por outro lado, integrando isto, nós vamos efetivamente permitir que todos os atores, que sejam beneficiários ou participantes, se deem conta de que eles não são senão trajetórias, desenvolvimentos, trajetórias de evolução.

Isto quer dizer que a formação deve provir disto, deve provir de um sequenciamento pedagógico, um pouco por recaminho e não por recaminho de competências, mas sim por recaminho de, passo a passo, ir colocando as bases que fazem com que eu ouse ser curioso, porque é sempre desestabilizadora a curiosidade, para si e para o outro, porque aceitar ser capaz de contemplar o outro é também receber mensagens que vão de encontro às suas próprias representações, se dando conta de que em seu domicílio fixo, ninguém é tão pobre que viva na rua, ele também, em algum lugar, tem um habitat, quer dizer, requestionar meu modo de morar, ele também pode ter um estado prostrado de desejo e pode ter feito escolhas, isto é, sua situação, que eu... começo a analisar assim de fora, como uma espécie de consequência de um sistema... que pode ser um sistema de crise econômica, de crise social, mas por vezes de maneira profunda, que talvez este indivíduo...se tenha posicionado em termos de escolhas deliberadas, nem sempre é o caso, é claro, mas isto quer dizer que em um certo momento, cada pessoa junto à qual eu atuo, é específica, eu não posso arrumá-la em gavetas, eu não poderia dizer, olhe, já que agora eu estou um pouco melhor em antropologia, eu tenho alguma compreensão, eu fecho a gaveta das pessoas que vêm, sei lá, do Malí, para a encontrar trabalho, eu puxo a gaveta das populações rom, com ou sem nível de representação, a gaveta dos deficientes.

Não, eu posso ter conhecimentos globais, mas é preciso que eu aceite que cada pessoa com a qual eu vou atuar, percorrer um longo caminho na minha missão profissional, é uma pessoa singular como eu, no olhar de cada um deles eu sou uma pessoa singular em evolução e nós vimos isto se retraduzir no processo pedagógico.

Por conseguinte, as sequências na relação com o outro que permitem, passo a passo, colocar a perda, não ter medo de ir mais longe no questionamento e na aceitação desta questão, e uma vez que estamos nessas sequências que permitem passo a passo abrir-se e aceitar a singularidade sistemática do encontro, mas isto quer dizer que as... dinâmicas pedagógicas em cada sequência foram mais assentadas em um enfoque interativo e dinâmico situacional, experimental, certamente, por meio de dramatizações, encenações, tempos de observação participante em serviços diferentes do meu, quer dizer, eu vou deslocar meu pessoal profissional para evitar a representação. Essas experimentações e em cada sequência, esta oficina, estes jogos, estas simulações, uma vez que os estagiários estão envolvidos, que já experimentaram, nós viemos trazer a informação complementar, a saber, nós não podemos deixar mais apenas a leitura do que é talvez simulação ou encenação, nós temos também que trazer alguma referência teórica, para que se possa assentar a reflexão e então todas as ferramentas que nós utilizamos em uma sequência, são ao mesmo tempo ferramentas, descobertas de si mesmo pelos estagiários, mas também oportunidades que eles podem reaplicar, depois, junto a cada beneficiário e cada idoso, sabendo que não há conclusão sistemática, pois cada um vai expressar, por meio das situações e das experiências, o que é sua singularidade e sua trajetória. 
Interface - $\mathrm{Na}$ Europa, assim como em outros lugares, não há simetria no significado que se dá aos diferentes grupos populacionais, por exemplo, entre o europeu e os imigrantes, ou em relação à população rom. Isto faz com que não haja simetria também na relação e cuidado a esses grupos. Ao pensar a formação de trabalhadores para o cuidado às populações vulneradas, como vocês pensam este problema?

Xavier Baylac - De fato o que você diz, aliás, é como efetivamente ultrapassar o modelo determinado para tentar aceitar que todos estão em equilíbrio, evidentemente, não estamos aqui para produzir a marcha forçada da integração e não é uma relação simétrica, justamente, a integração é, eu determino, eu tenho um modelo fixo de peças dos jogos que fazem com os rom, karanes, crioulos e, seja quem for, o outro tem que tomar a forma que minha sociedade espera dele.

Este modelo, hoje, de integração, qualquer que seja a população, não pode mais ser possível, portanto isto quer dizer que vai ser necessário que se chegue a colocar uma relação que faça com que as digitais originais e as digitais aceitas, cada uma ceda um pouco, de modo que, efetivamente, haja um encaixe, e é preciso aceitar que o encaixe não seja perfeito, pois efetivamente as coisas são singulares, mas não se pode mais forçar encaixar, portanto o movimento é..... de mandar corrigir os dois pontos de partida, o de quem acolhe e o de quem chega e tentar efetivamente estabelecer uma forma de simetria na relação, estou de acordo, acréscimo poderoso para falar da busca do equilíbrio, sabendo-se que este não é uma maneira espontânea, a definição de equilíbrio é que ele não é nada mais que um instante, então isto quer dizer que nos acontece também de reconjugar, de conjugar, de adaptar esta espécie de colocação progressiva em equilíbrio, aceitando que às vezes isto também não funciona, aliás, é aí que está um pouco de toda a dificuldade.

Vou dar um outro exemplo, na França, no quadro da ação social, uma grande parte foi revisitada pela lei nacional em 2002 e em 2005. A lei dizia, ou lembrava, que o indivíduo que é ajudado, seja no hospital, seja no retiro de aposentados, seja em um centro para jovens trabalhadores imigrantes, mesmo em casa, a pessoa é raramente independente. Ela deve estar no coração do dispositivo, ela é o elemento central e toda ação social deve efetivamente construir uma articulação para levar em conta esta pessoa em sua globalidade e desenvolver, propor, um acompanhamento na globalidade, é o que diz a lei.

E então a lei diz, devemos colocar a pessoa no centro, isto é, refletir o projeto pedagógico, o projeto institucional e social, levando em conta este lugar central da pessoa, a lei diz isso, todos os estabelecimentos revisitaram seus processos de acompanhamento neste quadro e o diretor hoje é responsável pela ação social e ele diz que sim, colocamos a pessoa no meio, colocamos a pessoa no meio para tentarmos nos agrupar em torno dela, mas de fato isto foi traduzido porque, a realidade é técnica, ou seja, uma enfermeira tem que realizar em uma hora, quinze cuidados...é quase produtividade.

O trabalhador social ou... como eles se chamam, os cuidadores, nos retiros de aposentados e nos hospitais, em uma hora têm de fazer quinze cuidados higiênicos dos doentes, fazer quinze leitos dos doentes, portanto nós temos este parâmetro e ao mesmo tempo dizemos, nós colocamos a pessoa no meio, nós construímos o sistema para ela, tentando levar em conta diretamente, mas os modos de funcionamento de cada instituição são de tal maneira sem normas, que de fato, sim, colocamos a pessoa no meio, mas colocando-a no meio desta maneira, nós nos afastamos dela.

Nós a colocamos no centro para criar uma espécie de corrente integrada, permitindo encontrar a resposta, mas o impacto que isto produziu foi, de fato, colocá-la no meio de um círculo que se ampliou de tal maneira que, ao contrário, ficou mais distanciado dela agora do que anteriormente e é isto que desfoca, temos de recorrigir em algum lugar, ou seja, temos que nos dizer: atenção, se nós banalizarmos a intervenção social, a intervenção de saúde, se nós não formos fiéis senão em matéria mais propriamente técnica ou de repente demasiado assimétrica, se resta ainda uma explicação, nós estamos perdendo o porquê de estarmos lá e quem pode realmente dizer, aí está, nós tentamos nos recolocar num momento para nos religarmos à pessoa que estava melhor, senão... o trabalho social ou o trabalho da saúde vai se tornar, é claro, um pouco... instigante, mas vai se tornar um trabalho de fábrica, isto é, efetivamente nós vamos produzir o ato cumulativo, mas nós não vamos responder ao acompanhamento das melhoras da pessoa ou ao bem-estar...nós estaríamos perdendo a definição 
da Organização Mundial de Saúde, mas ao mesmo tempo não a estaríamos perdendo, por causa da lógica do trabalho em conjunto, observem que existe hoje em dia um grande desafio de poder, sem colocar em causa o sistema, porque não é nossa vocação, em todo caso, de poder trazer elementos de correção adaptada para readquirir essa simetria na relação entre o usuário e o beneficiário, o profissional da saúde e o profissional da ação social.

Interface - Eu creio que o trabalho de rede é muito importante, e para nós fazermos uma reunião aqui, em dois dias, cinco países, cinco idiomas diferentes, é um esforço importante para manter o diálogo e o trabalho. Você pode falar um pouco sobre as dificuldades do trabalho de rede, mas também sobre as vantagens, as possibilidades que existem para o trabalho de rede.

Fantxoa - Eu penso que é uma questão de equilíbrio, as dificuldades que a diferença de parceria geram... são estas dificuldades que trazem aqui uma forma de riqueza, seriam que, tecnicamente, nós somos oito parceiros de cinco países, portanto já há cinco línguas oficiais, como o italiano, o eslovaco, o inglês, o francês, o espanhol, às quais se adicionam de fato as línguas visuais, para alguns dentre nós, pode ser o romani, pode ser o catalão, pode ser o basco, línguas portanto, que dentro do que explicamos, dentro do que tentamos trazer em termos de valor, da relação, da ligação com o outro... no cotidiano, são línguas que passam tanto quanto o francês, eu diria por exemplo, que entre nós, no País Basco, na relação notadamente com os idosos, a língua basca tem tanto lugar quanto o francês.

A capacidade linguística muito grande, esta é a nossa riqueza e certamente é também a dificuldade prática, o fato de que não há uma única língua comum, que é utilizada pelo conjunto de pessoas que participam do projeto, vocês sabem que nós temos mais tendência a termos projetos que emergem na Europa, nos quais a língua inglesa é a única utilizada, porque é mais fácil, é uma regra bastante comum, que faz com que a língua inglesa seja a língua de trabalho, então todos o atores que participam deste projeto falam inglês, é muito mais fácil, mas também de algum modo isto empobrece, isto desnatura, como diz Xavier, isto muda um pouco o sentido do trabalho e da proposta, primeiro porque reduz expressivamente o número de pessoas com capacidade, com competência para poder serem atores, se apenas pessoas que falam inglês podem participar deste projeto, ele então não seria o que é, porque a maioria das pessoa não fala inglês.

Então isto reduz, isto empobrece, isto desnatura expressivamente o próprio sentido do projeto, então nossa escolha é de um tipo em que o plurilinguismo possa ser, na medida do possível, levado em consideração, então tecnicamente, o que nós fazemos (o que complexifica e torna a coisa mais pesada e mais difícil no cotidiano) é usar duas línguas, no mínimo, o francês e o inglês, sabendo que o eslovaco também é uma língua utilizada, pois certos atores eslovacos não falam nem francês, nem inglês, portanto nós temos de fato três línguas de trabalho, com a necessidade, nosso impasse, as respostas técnicas em relação a isto, temos então sistemas de tradução, que são certamente úteis e que fazem com que o conjunto do grupo possa trabalhar, tornar-se mais complexo, mais amplo e miscigenado.

\section{Interface - Fale um pouco do trabalho e compromisso de cada um em torno do desenvolvimento do projeto.}

Fantxoa - Temos dois grandes tipos de perfil, o dos pedagogos e das pessoas que são efetivamente fomentadoras, e o perfil dos profissionais que já trabalham em linha direta com o público, os cuidadores, de sorte que um dos interesses deste tipo de procedimento é de conseguir articular esses dois enfoques em um conjunto, pois me pareceria irrisório que os pedagogos pudessem sozinhos definir um cronograma, um processo que fosse eficaz, que fosse eficiente, sem que os atores do campo, que vivem a realidade cotidiana e notadamente, também, a realidade do lugar do outro, sem que os profissionais não estivessem lá para trazer o seu esclarecimento, seus próprios objetivos.

Xavier Baylac - Como complemento ao que disse Fantxoa, a construção de nosso espaço colaborativo, efetivamente, é uma espécie de processo de concertação interativa permanente porque 
ninguém é detentor de uma matéria absoluta, de uma certeza, em todo caso, dentro do que é preciso que se possa permitir ao sistema, ao qual eles vão efetivamente se adaptar, ao profissional, de evoluir neste sistema com uma nova capacidade, uma nova postura, pois a coprodução, a construção colaborativa é um processo que leva um pouco de tempo, mas que em todo caso garante uma espécie de boa adequação, entre o que é possível de se fazer na formação e o que é esperado da intervenção do profissional.

Toda a arte do exercício, como num processo de concertação clássica, não está na concertação, que é complexa, é a regulação, porque o risco da concertação permanente pode fazer com que fiquemos em reflexão permanente.

Ora, num momento é preciso ousar também, fixar os objetivos de aplicação, e então nós vamos fixar linhas sobre este número de trabalhos, aceitando o risco de não sermos perfeitos, mas, em todo o caso, de podermos ter sucesso por meio de trocas praticadas, atestadas, experimentadas, para reintegrá-las, reinterrogá-las em termos de avaliação, isto é, sabemos que a maquete que vai ser nossa maquete original, a primeira entre as que se definiram neste momento e aquela que terá matéria conclusiva dentro de doze, quinze meses, ela vai se alterar, mas ela vai se alterar pelo fato de que nós aceitamos esta imperfeição relativa no início, para poder trazer todos os pontos de correção progressiva, no real da experiência, isto é, no real de como vocês veem os profissionais, quando eles vão tentar se questionar, quando eles vão começar a formação, quanto ao que eles vão nos contrapor: mas não, eu fui formado, mas não, eu... pensei diferentemente.

Quando eu trabalho com o beneficiário, o idoso, o paciente, eu me dou conta de que isto demanda alteração, pois efetivamente nós vamos integrar dois parâmetros de avaliação, o dos profissionais, que vão estar imersos, e o dos beneficiários, junto aos quais os profissionais vão se formar, o que faz com que haja, sim, concertação, progressão na construção, com esta capacidade de poder num momento recalibrar as coisas progressivamente, para ficarem mais exatas, menos afastadas... mas isto significa que, efetivamente, é preciso também que nos fixemos, algumas regulações, mesmo que num certo momento posamm surgir pontos que fiquem em suspenso, aceitemos que fiquem em suspenso, mas enquanto isto vamos construindo, avançando e colocando os marcos passo a passo.

Fantxoa - A Europa nos financia durante dois anos para que nós tenhamos a capacidade de nos projetar e de dizer, ao cabo desses dois anos, que as ferramentas que produzimos e que vamos emitir, como é que elas vão ter um lugar na panóplia da formação na vida da Europa.

Nesta fase, por enquanto, nós não estamos ainda com capacidade de nos projetar de maneira formal sobre o futuro desses produtos, o que nós sabemos é que as ferramentas que vamos produzir serão integradas no percurso dos processos de formação, que nós mesmos não podemos alavancá-los, é uma palavra sem dono, porém agora a questão estratégica corresponde a se dizer, de que maneira, a partir desses dois anos de experimentação, podemos fazê-los viver, com esta mesma dinâmica, além dos dois anos, como é que nós nos projetamos sobre as perspectivas mais internas.

Xavier Baylac - O que estamos capacitados para produzir é da ordem de saber, de compreender claramente os meandros da exploração do projeto, porque efetivamente, partilhando, cada um de nós, necessidades muito físicas, específicas do trabalho de campo, o que vamos produzir cada um vai utilizá-lo no quadro da formação de seus próprios profissionais e de suas próprias equipes, pois nós não temos neste projeto, como sempre ocorre, uma colaboração europeia, mas é verdade que já ultrapassamos um marco, o que vale dizer, temos certeza de que cada um de nós utilizará o resultado do outro, o que é já um avanço significativo, este é o primeiro ponto.

O segundo ponto é esta energia que se expandiu a partir de uns e de outros, esta riqueza de hemisférios diferentes, nos demos conta e alguns dos exercícios que foram produzidos ontem nos levaram a estimar que tínhamos, apesar de nossas diferenças, de nossas exportações, de nossos posicionamentos, geraram (os exercícios) uma espécie de espaço de pensamento prospectivo, que este espaço de reflexão prospectiva. Tem o mérito de cair em boa hora, já que cada um dentro de nossos sistemas, seja da saúde, seja social, já que estamos com as agencias regionais, mas os sistemas são internacionais. 
Observem qual é o desafio que está além do que nós vamos fazer, cada um de nós, ao levar a efeito a formação, o que em si é fácil, o desafio é como este consórcio pode perdurar, se enriquecer, isto é, nós não temos vocação para ficar sós e devemos também nos juntar, talvez a outros atores de nosso universo, porém a atores de uma, de outra esfera e se nós quisermos construir uma espécie de esquema, de desenvolvimento durável, de nossa sociedade, de uma sociedade que repouse sobre a simetria, sobre o equilíbrio, sobre as equidades de uma maneira global, é preciso que nós incorporemos à questão da saúde e do trabalho social.

Cabe aos nossos parceiros do mundo econômico, também para que efetivamente sejamos, o que chamamos na França dentro de nossa reflexão, um enfoque integrado da ação sanitária e social, isto é, a construção de todo um tecido de respostas possíveis que venham apoiar a problemática individual das pessoas em condição de fragilidade.

Mas este consórcio, tal como o vejo evoluir, em relação ao que pode chegar a ser um assunto na França, em nível nacional, eu digo para mim mesmo, que mediante esta riqueza de atores, esta diferença, esta diversidade, existe aí, ou a possibilidade para o consórcio de se tornar uma espécie de laboratório permanente de inovação dentro da prática dos profissionais, ou senão uma espécie de think tank, também porque temos posturas e um pouco de responsabilidade de sermos um ator, permitindo ao poder público, político, quer se trate de comunas, de departamentos, de regiões ou de certas decisões dos estados sobre a organização da política social, de se tornar uma espécie de reservatório de ideias e por isso eu utilizo a palavra think tank, mesmo que efetivamente ela seja, possa permitir de se contaminar um pouco, mas eu acho que este consórcio tem esta vocação de ...poder perdurar, eu acho que será necessário que ele se enriqueça, senão haverá o risco de nós mesmos reproduzirmos um sistema fechado, isto é, nós partimos de uma lógica que era de se abrir, em todo caso, de falar às claras, como um elemento forte de todas as nossas reflexões, o risco é que se nós não produzirmos senão esta abertura contra nós, em tudo que fazemos, nós teríamos a argila entre nós, mas ficaríamos no nosso próprio âmbito.

Portanto, eu penso que é preciso que chegue o momento em que venhamos percutir outras atividades, outros domínios que não o nosso e que venhamos a ouvir o que o resto da sociedade tem a dizer sobre o acompanhamento social e o acompanhamento sanitário e que de repente isto possa se tornar uma espécie de laboratório de inovação permanente, ou então e porque não, um reservatório de ideias de transposição política.

\section{Interface - Você tem alguma coisa que queira falar, fatos sobre o trabalho, sobre as relações com os parceiros...}

Xavier Baylac - Trabalhando com o outro, nós descobrimos passo a passo uma marcha, pari passu com nossas dificuldades, porque o projeto, esta espécie de construção por etapas, cada etapa, ao mesmo tempo que ela produz, ela corresponde também a uma espécie de parto, o que faz a concertação é que tudo aquilo que foi necessário mexermos, tudo aquilo que foi necessário ... revisitarmos as certezas, alterando nossas linhas, ou seja, em algum lugar as nossa defesas naturais como 'eu estou praticamente seguro de mim, eu conheço minha profissão', mas foi preciso se dizer 'ah, talvez, talvez eu soubesse das coisas, mas talvez seja preciso que eu as adapte'.

Por conseguinte este processo nos leva num momento determinado a atravessar momentos complexos de fadiga, de cansaço, três horas para chegar a definir um calendário, no fim de três horas... o esforço, a vontade de lhe dizer, eu vou talvez matar o parceiro... Se não o fazemos, é porque já estamos efetivamente muito apegados a... uma ambição que é de se dizer que é preciso poder produzir a mudança dos profissionais, em virtude do risco, sim, de gerar estados de fratura ainda maiores, mas isto funciona também, porque na relação humana, na relação de nossas humanidades respectivas, por meio desses processos, nós também vamos gerar espaços de crescimento e prazer e é isto que faz o projeto, isto é, que nós mesmos somos talvez os primeiros atores a testar as metas, antes mesmo dos profissionais em formação, os pré-profissionais em seu campo. Nós somos os primeiros a aceitar, a ter que aceitar esta alteração, esta espécie de movimento de nossas próprias linhas e com 
efeito, eu, que tenho que fazer um esforço, eu vou fazê-lo, mas é verdade que ela (a marcha) chegou, eu tenho um pequeno prazer, eu penso que eu vou suportar mais facilmente os golpes.

Palavras-chave: Sistemas de saúde e proteção social. Cuidado. Agentes de saúde. Formação. Projeto Kilt.

Keywords: Health Systems and social protection. Healthcare. Health workers. Education. Kilt Project.

Palabras clave: Sistemas de salud y proteción social. Atención. Trabajadores de salud. Formación. Proyecto Kilt.

Recebido em 28/04/15. Aprovado em 28/04/15. 